\title{
Binder-Iijima, Edda, Löwe, Heinz-Dietrich, Volkmer, Gerald, Die Hohenzollern in Rumänien 1866-1947 : eine monarchische Herrschaftsordnung im europäischen Kontext
}

Benjamin Landais

\section{OpenEdition}

Journals

Édition électronique

URL : http://journals.openedition.org/ifha/6677

DOI : 10.4000/ifha.6677

ISSN : 2198-8943

Éditeur

IFRA - Institut franco-allemand (sciences historiques et sociales)

Référence électronique

Benjamin Landais, « Binder-lijima, Edda, Löwe, Heinz-Dietrich, Volkmer, Gerald, Die Hohenzollern in Rumänien 1866-1947 : eine monarchische Herrschaftsordnung im europäischen Kontext », Revue de l'IFHA [En ligne], Date de recension, mis en ligne le 01 janvier 2011, consulté le 22 septembre 2020. URL : http://journals.openedition.org/ifha/6677 ; DOI : https://doi.org/10.4000/ifha.6677

Ce document a été généré automatiquement le 22 septembre 2020.

(C)IFHA 


\title{
Binder-Iijima, Edda, Löwe, Heinz- Dietrich, Volkmer, Gerald, Die Hohenzollern in Rumänien 1866-1947 : eine monarchische Herrschaftsordnung im europäischen Kontext
}

\author{
Benjamin Landais
}

1 Ce volume de douze articles adopte un angle d'attaque assez nouveau pour l'histoire contemporaine du Sud-Est européen : celui de l'action des rois roumains dans l'affirmation nationale et la modernisation politique et sociale de leur pays d'adoption. Des parallèles avec le cas de la Grèce et de la Bulgarie, qui ont aussi choisi une dynastie allemande pour les conduire sur la voie de la reconnaissance internationale, ne manquent pas concernant la première période. Cet exercice s'avère pourtant plus ardu qu'il n'en a l'air. L'historien doit en permanence se garder d'attribuer une influence exagérée au souverain dans la conduite de son royaume. Le rôle de ses attaches culturelles germaniques ne saurait non plus être surévalué. Une élite politique nationale continue - même dans la période de «dictature royale » - à imposer, sinon ses volontés, du moins le cadre du débat et des alternatives politiques qui peuvent être menées.

2 Mais lier trop solidement le trône à une évolution politique interne, faisant du monarque un simple spectateur, constituerait une erreur aussi grave. Naviguer entre ces deux écueils revient à s'interroger sur la voie d'entrée de la Roumanie dans la norme européenne en trois quart de siècle, comme État et comme société. Le roi reste un acteur majeur de la modernisation : dans l'armée, dans l'accompagnement des politiques d'alliance, dans la construction de la loyauté envers le nouvel État, dans le cérémoniel de cour. Entre la vie des partis et des courants d'opinion, une francophilie qui ne se dément pas et un nécessaire jeu de bascule entre les grandes puissances, un espace d'initiative propre aux Hohenzollern semble se dégager. 
3 Publiés à la suite du colloque sur la « dynastie des Hohenzollern-Sigmaringen en Roumanie 1866-1947 et les relations germano-roumaines » tenu à Heidelberg du 2 au 4 novembre 2006, ce recueil nous propose deux types d'approches complémentaires : une première série d'études, menées sur la longue durée, suit le fil conducteur de la modernisation interne et du statut international de la Roumanie. Les articles de K. Hitchins, G. Volkmer, C. Zach et L. Maier permettent de construire la monarchie en tant qu'objet historiographique et dessinent les rythmes de son évolution. Ceux de G. Klein, M. Kroner et E. Binder-Iijima se concentrent sur des domaines " royaux " par excellence que sont l'armée, le rapport avec les minorités allemandes et la culture de cour. Une seconde série d'analyses laisse, de son côté, toute la place à trois des quatre souverains. E. Siupur et I. Gregori consacrent leur article à Charles Ier dans ses rapports, respectivement, aux autres monarques des Balkans et au poète nationaliste Mihai Eminescu. Charles II, dont la politique et la personnalité continuent de nourrir les critiques, est au centre des études d'H.-C. Maner et de K. Heitmann. Après les dix ans de règne qui ont profondément entamé la crédibilité voire même la viabilité de la monarchie, A. Heinen s'interroge sur les derniers efforts de Michel Ier pour empêcher la chute de cette institution.

Benjamin Landais (université de Strasbourg, EA 3400) 